\title{
FIRST RESULTS OF PREDICTIVE CONTROL APPLICATION ON WATER SUPPLY AND DISTRIBUTION IN SANTIAGO-CHILE
}

\author{
G. Cembrano* , J. Quevedo*, V. Puig*, R. Pérez*, J.Figueras*, \\ G. Ramónn ${ }^{\#}$ P. Rodríguez ${ }^{\#}$, G. Barnet ${ }^{\#}$, M. Casas ${ }^{\#}$, J. M. Verdejo ${ }^{\#, ~ A . ~ G i l ~}{ }^{\#}$ \\ J.Martí , H. König \\ 'Instituto de Robótica e Informática Industrial (UPC-CSIC) \\ Llorens i Artigas 4-6, Planta 2 - 08028 Barcelona, Spain \\ gcembrano@iri.upc.es \\ *Dept. Enginyeria de Sistemes, Automàtica i Informàtica Industrial \\ Universidad Politécnica de Cataluña-Campus de Terrassa \\ Rambla Sant Nebridi, 10 - 08222 Terrassa, Spain \\ ${ }^{*}$ Clavegueram de Barcelona S.A. \\ Acer, 16-08038 Barcelona, Spain \\ 'Aguas Andinas S.A. \\ Avda. Presidente Balmaceda 1398, Santiago, Chile
}

\begin{abstract}
This paper deals with the use of predictive optimal control techniques for flow management in a large water system including reservoirs, open channels for water transport, water treatment plants, pressurized water pipe networks, flow/pressure control elements and a telemetry/telecontrol system. Predictive control is used to generate flow control strategies from the sources to the consumer areas to meet future demands with appropriate pressure levels, optimizing operational goals such as network safety volumes and flow control stability. Copyright C 2005 IFAC
\end{abstract}

Keywords: Real-time control, Water systems, Predictive control, Optimal control.

\section{INTRODUCTION}

Drinking water management in urban areas is a subject of increasing concern as conurbations grow. Limited water supplies, conservation and sustainability policies, as well as the infrastructure complexity for meeting consumer demands with appropriate flow pressure and quality levels make water management a challenging control problem. The problems related to modelling and control of water supply and distribution have been the object important research efforts in the last few years (e.g. Brdys and Ulanicki, 1994, Cembrano et al. 2000, Maksimovic, Butler and Memon, 2003).
Water systems are usually comprised of :

- Supplies, where raw water is drawn from superficial or underground sources, such as rivers, reservoirs or boreholes

- Production facilities, where water is treated to meet consumer-use standards

- Transport systems, consisting of canals and other natural or artificial open flow conduits which carry water from the sources to the treatment sites and to the distribution areas

- Distribution areas, including consumer demands, storage tanks and pressurized pipe networks, to which water must be supplied with appropriate pressure levels 
- Pressure and flow control elements in all the above-mentioned subsystems, which make it possible to meet demands with the available resources (gates, valves, pumps, etc)

Many modern water systems are operated through centralized or distributed telemetry and telecontrol. Water supply, treatment, transport and distribution are often operated separately, by different authorities. Planning and management of these subsystems have different goals and time-scales. Additionally, the hydraulics involved differ considerably from one another, in particular, between large spatially distributed open channel areas and pressurized water sections for distribution to consumers.

This paper describes the first results of an on-going collaborative project between Aguas Andinas, the company in charge of water supply and distribution in Santiago-Chile, CLABSA, the urban drainage company in Barcelona, and the Technical University of Catalonia. The objective of the project is to apply predictive optimal control techniques in the largescale Santiago water system, to produce comprehensive control strategies for the supply, treatment and transport sections simultaneously. Previous contributions of the authors in this field have been background material for this project (Cembrano et al. 1988, 2000, 2004).

Section 2 describes the modelling and predictive control approach, Section 3 describes the case study of Santiago-Chile and Section 4 summarizes the conclusions and further research.

\section{PREDICTIVE CONTROL IN A WATER SUPPLY AND DISTRIBUTION SYSTEM}

\subsection{Control Scheme}

In a supervisory control system for a water network, the optimal control procedure interacts with the real network through the SCADA (Supervisory Control and Data Acquisition) system. It must receive information about the current state of the network; in particular, water volumes in reservoirs, status of pumps and valves, latest demand readings, and pressure/flow readings at selected points. Additionally, for open channel sections, previous flow values in the upstream end must be stored. In general, SCADA systems in large water networks provide readings of the whole network at intervals of the order of 1 hour

In order to compute optimal control strategies ahead of time, the predictive control procedure contains:

- a prediction model to generate forecasts of the next future demands, based on a record of a number of the most recent past values thereof. A number of methods for demand prediction may be used as described elsewhere (Quevedo, Cembrano, Casanova \& Gutiérrez, 1988; Griñó 1991)
- a hydraulic model of the network which makes it possible to compute the effect produced on the network by an action at the control elements.

The predictive control procedure selects optimal strategies for the controllers of the active hydraulic elements, by searching in the space of possible controls and evaluating different alternatives.

Different control alternatives must be evaluated and rated for their overall effects during a future period of time, for example, a whole-day operation period, called the optimization horizon. An optimization procedure selects the best control strategy for the next optimization horizon, using a cost function to rate the control alternatives. The optimal control values are then sent through the SCADA as setpoints to the local controllers in the pressure and flow control elements in the network

In the Santiago system, a sampling time (and control interval) of 1 hour is used, based on the scanning time of the telemetry system. An optimization horizon of 24 hours is chosen, taking into account the current operational needs, as wells as the transport delays between the supplies and the consumer sites.

The computation of optimal strategies must take into account the dynamics of the complete water system and:

- 24-hour-ahead demand forecasts

- 24-hour-ahead availability predictions in supply reservoirs and aquifers

- Current state of the water system

- 24-hour historic data in open channel sections, due to delays in water transport

- physical and operational flow constraints in all elements.

\subsection{Control goals}

The immediate objective of a water supply system is to meet the demands at consumer sites with appropriate pressure levels, according to users' needs. The predictive control system must compute strategies which achieve this, while optimizing the system performance in terms of:

- Network safety

- Set-point stability

- Cost reduction

- Conservation and other policies

\subsection{Modelling the network}

A convenient description of the dynamic model of a water network is obtained by considering the set of flows through the $m$ active elements as the vector of control variables

$u \in R^{m}$

and the set of $n_{r}$ reservoir volumes monitored through the SCADA as a vector of observable state variables

$r \in R^{n_{r}}$ 
.Additionally, in order to complete the state description of the network, it may be necessary to define a vector

$q \in R^{n_{q}}$

containing the values of flow at $n_{q}$ specific passive elements, which cannot be directly measured through the SCADA and a vector

$p \in R^{n_{p}}$

containing the values of pressures at $n_{p}$ specific nodes, not monitored through the SCADA.

Vectors $p$ and $q$ may be obtained from $r$ and $u$ through explicit or implicit, generally nonlinear, equations. For open channels, these equations include the channel flow dynamics. For pressurized pipes, they express the hydraulic head-flow relationship. Hence,

$p=h(r, u, d)$

$q=g(r, u, d)$

where

$d \in R^{n_{d}}$

is a vector of stochastic disturbance containing the values of the demands at the $n_{d}$ consumer nodes in the network.

Since the model is used for predictive (optimal) control, $d$ will generally be a vector of demand forecasts, obtained through appropriate prediction models.

An augmented state vector is defined as

$$
\begin{aligned}
& x \in R^{n} \\
& n=n_{r}+n_{q}+n_{p}
\end{aligned}
$$

where $x$ contains the $n_{r}$ values of reservoir volume vector $\boldsymbol{r}$, the $n_{q}$ values of the flow vector $q$ and the $n_{p}$ values of the pressure vector $p$.

Finally, the dynamic model of the network may then be written, in discrete time, as:

$$
x^{k+1}=f\left(x^{k}, u^{k}, d^{k}\right)
$$

where $f$ represents the mass and energy balance in the water network and superindex $k$ denotes the instantaneous values at sampling time $k$.

\subsection{Predictive Control Approach}

The computation of the optimal control setpoints to be applied at the actuators is based on predictive control (Camacho and Bordons 1999, Maciejowski 1999, Mosca 1995). More precisely it applies the receding horizon strategy. This consists of determining a virtual control input sequence of present and future values $\left(u^{k}, u^{k+1} \ldots, u^{k+N-1}\right)$ that optimizes an open-loop performance function, according to a prediction of the system evolution over the horizon $N$. This prediction is performed assuming that disturbances (rain measures) and model parameters (no adaptation) will keep constant during the horizon. However, only the first control input of sequence $\left(u^{k}\right)$ is actually applied to the system, until another sequence based on more recent data is computed as shown in Fig.1. The same procedure is restarted at time $k+1$, using the new measure ments obtained from sensors and the new model parameters obtained from the recursive parameter estimation algorithm that is working in parallel. The resulting controller belongs to the class called open-loop optimal-feedback control. As the name suggests, it is assumed that feedback is used, but it is computed only on the basis of the information available at the present time.

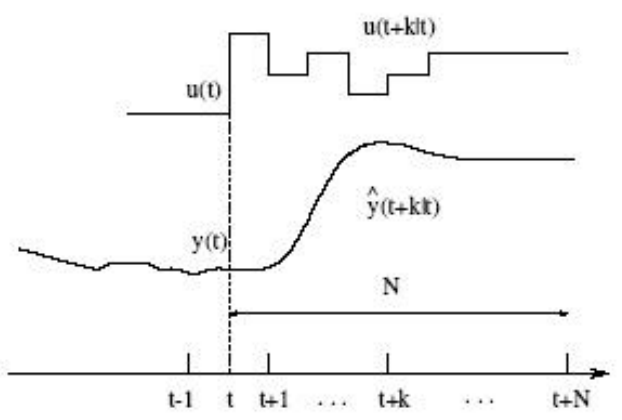

Fig. 1 Predictive Control Strategy

\section{CASE STUDY: THE SANTIAGO WATER NETWORK}

\subsection{Network description}

The Santiago water network supplies water to approximate 4 million consumers. The main supplies come from a number of mountain sources, such as natural or man-made reservoirs. Water reaches 4 main treatment plants through rivers and canals. It takes approximate 12 hours for water to go from the sources to the plants.

After treatment, water is transported to consumer areas through three aqueducts. Consumer areas draw water from the aqueducts and use tanks, valves and pumps to achieve appropriate pressure and flow levels. Many areas also dispose of alternative underground water sources.

The complete supply and transport network has been modelled using: 2 mountain reservoirs, 4 treatment plants, 186 open channel sections, 281 pressure mains, 99 tanks, 88 valves and 39 pumping stations. The whole water network is controlled through a supervisory control and data acquisition (SCADA) system with sampling periods of 1 hour. For the predictive control scheme a prediction horizon of 24 $\mathrm{h}$. and a history of the previous $24 \mathrm{~h}$. are chosen. 
The network model and its predictive optimal control have been implemented in an operational planning tool developed by the research group, which creates the optimal control problem equations and uses a commercial solver (GAMS,97) to compute a solution through nonlinear optimization techniques.

The complete optimization problem has been solved successfully off-line in a number of scenarios. Its online implementation is currently underway.

A simplified version of the Santiago network is shown in Fig. 2. Water from the mountain supplies ALN EYeso is transported to the treatment plants VVT and PFLORIDA and then to the consumer areas TOC; VARAS and CONT, through a series of open channels and aqueducts (blue lines) and pressurized sections (black lines). Consumer areas contain tanks ETOC, EVARAS and ECONT, which store water to meet demands. This simplified network has been useful to study the network operation and the first results of applying predictive control on this network are presented in the following sections.

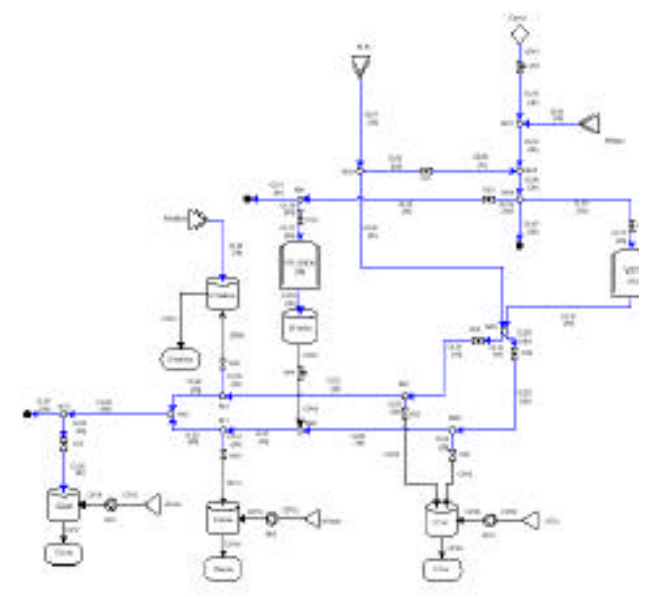

Fig. 2. Simplified version of the Santiago network

\subsection{Test Scenarios}

Two test scenarios have been chosen to show the predictive control performance. The first one reproduces a sudden drop in the demand, which occurs due to unexpected weather changes in the summer. Fig. 3 shows the hourly demand curve at one consumer point for three days.

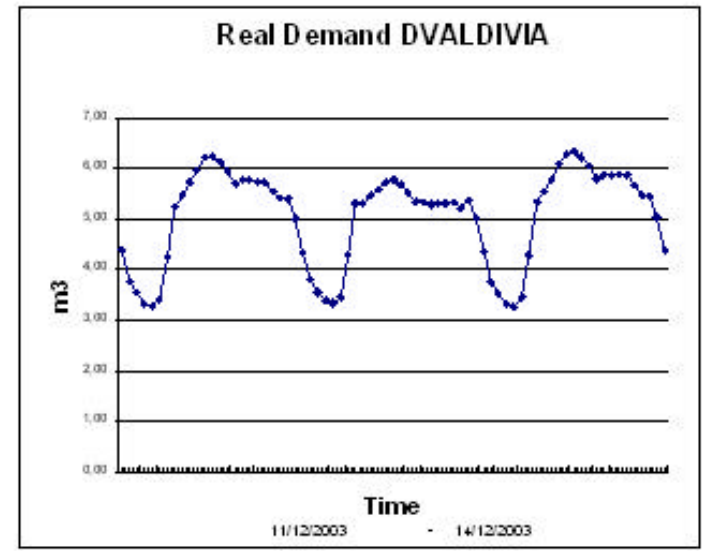

Fig. 3. Demand curve at one consumer point

The second one corresponds to a decrease in the production plant availability. This effect is usually caused by an increase in the turbulence of incoming water, as a result of heavy rains upstream of the treatment plant.

\subsection{Results}

The results of the predictive control application on the simplified network for test scenarios 1 and 2 are shown in the following figures

Figures 4 to 8 correspond to the first scenario. Figures 4 and 5 show the treatment plants output VVT and PFLORIDA evolve regularly, without abrupt changes, as suits the operational needs.

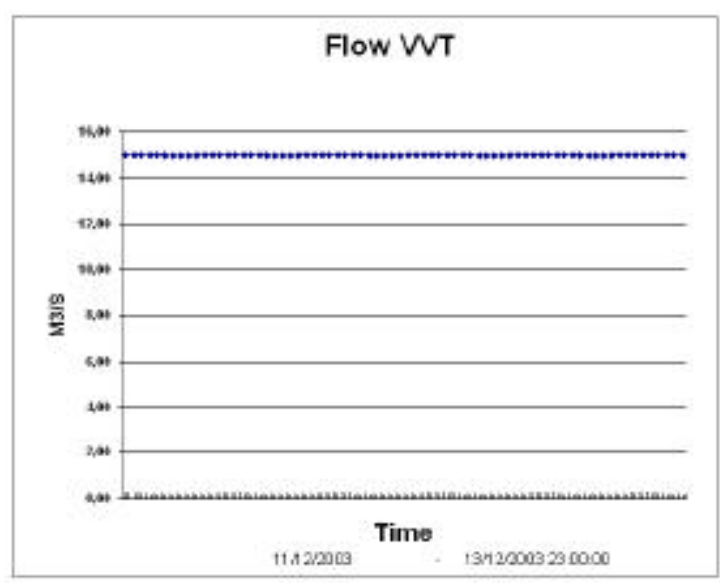

Fig. 4. Treatment plant output VVT 


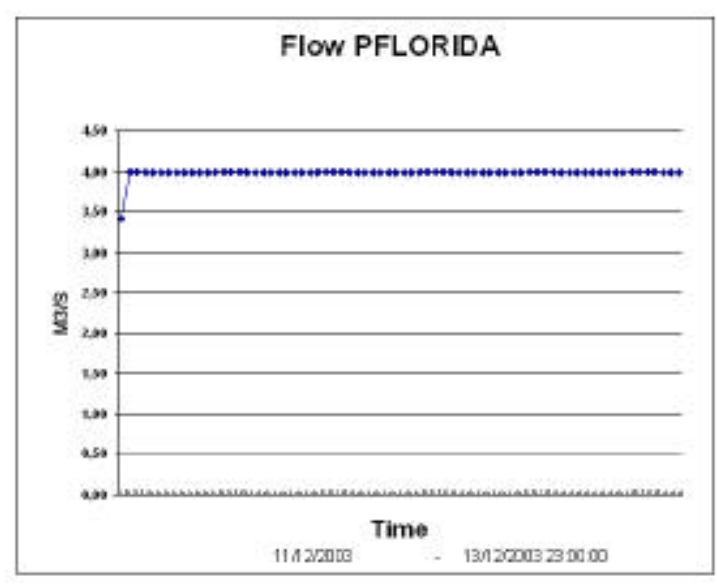

Fig. 5. Treatment plant output PFlorida

Figure 6 shows the water flow into one of the aqueducts (CL19).

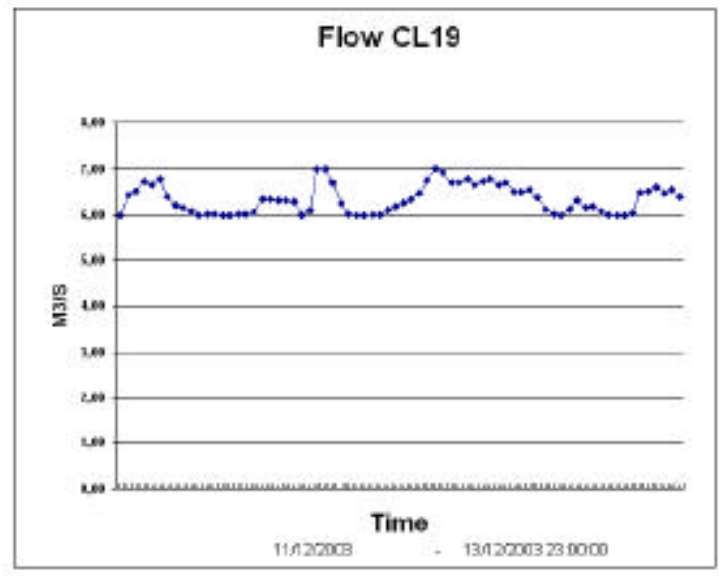

Fig. 7.Water flow into main aqueduct CL19

Figures 7 and 8 show the evolution of two important tanks (EVARAS and ETOC).

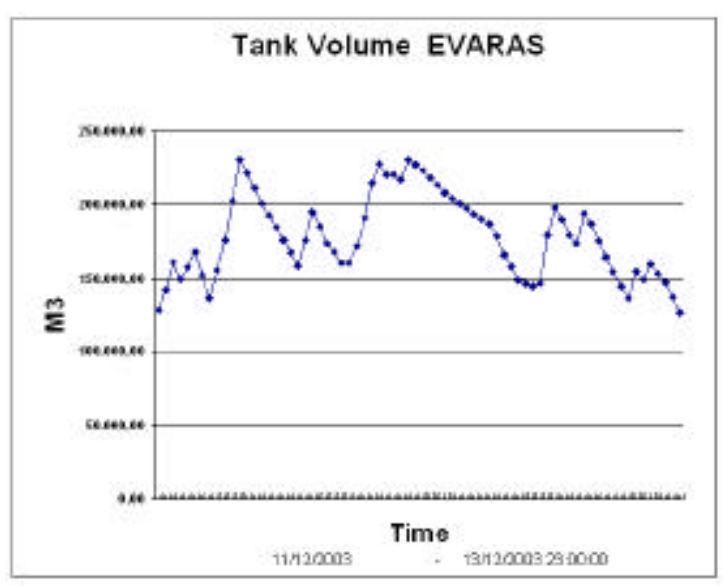

Fig. 7. Tank Volume Evaras

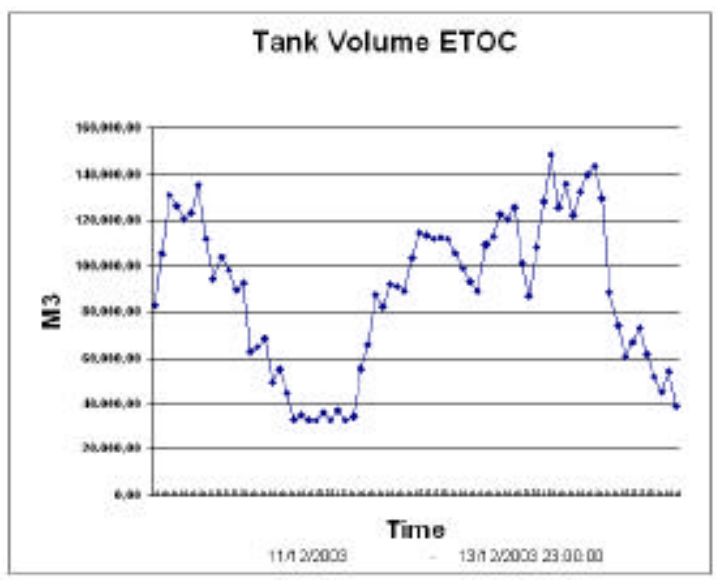

Fig. 8. Tank Volume Etoc

Figures 9 to 12 correspond to the second scenario. Figure 9 show the main treatment plant output, which drops to a lower level for a period of 5 hours on the second day.

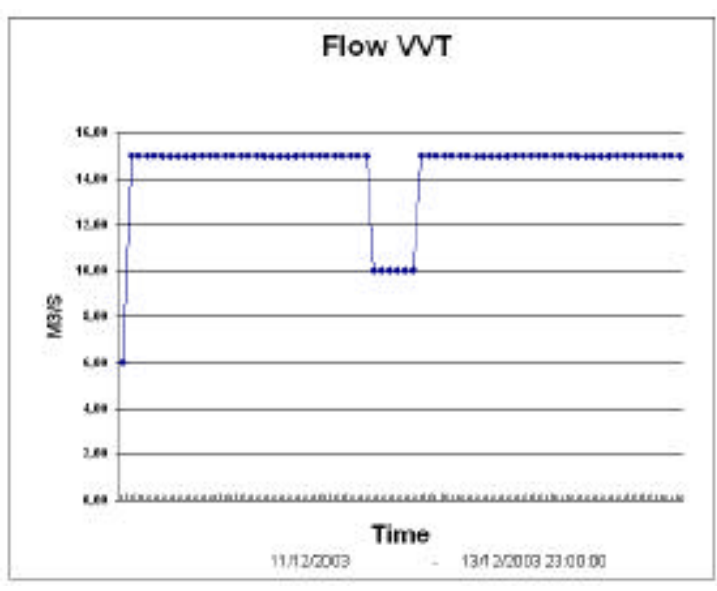

Fig. 10. The tratament plant output VVT

Figure 10 shows the flow into the aqueduct which drops due to the decrease in the treatment plant output. The effect is delayed due to the transport effects in the open channels between the treatment plant and this point.

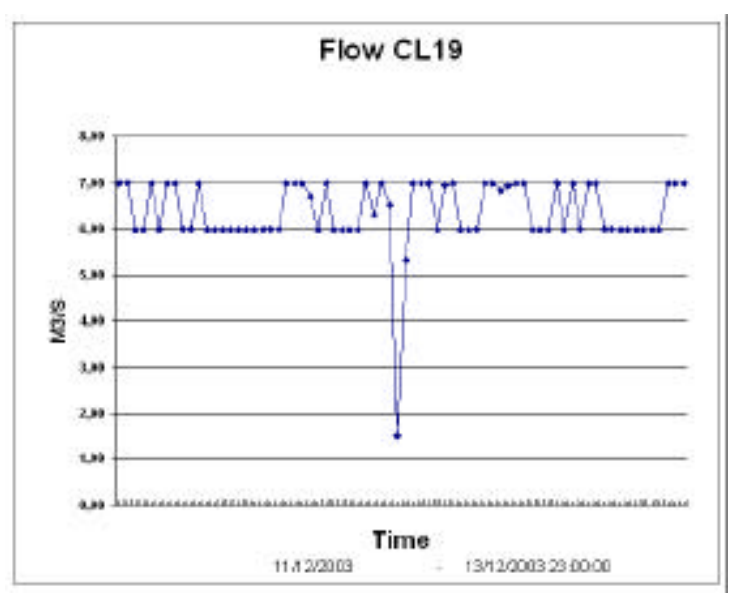

Fig. 10. Water Flow into main aqueduct CL19 
Figures 11 and 12 show the evolution of reservoirs EVARAS and ETOC in this scenario. A clear effect of the production drop may be observed, as more water must be drawn from the tanks to meet the demands.

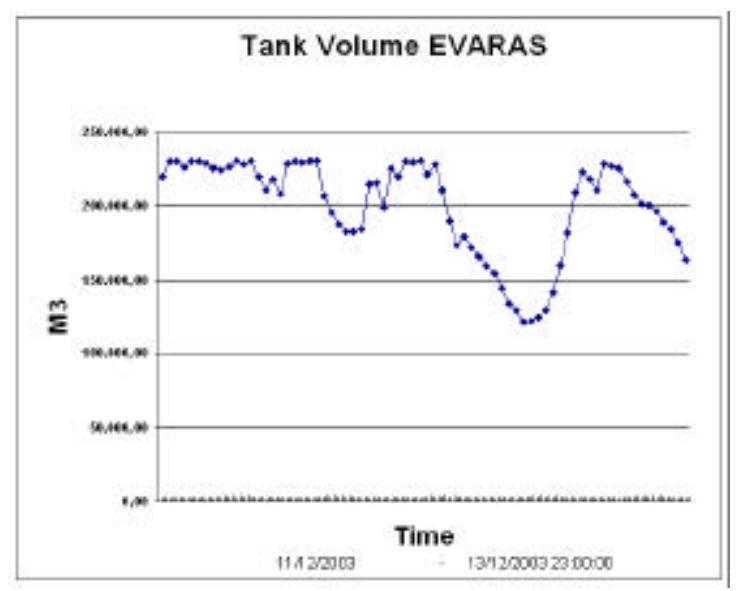

Fig. 11. Tank Volume Evaras

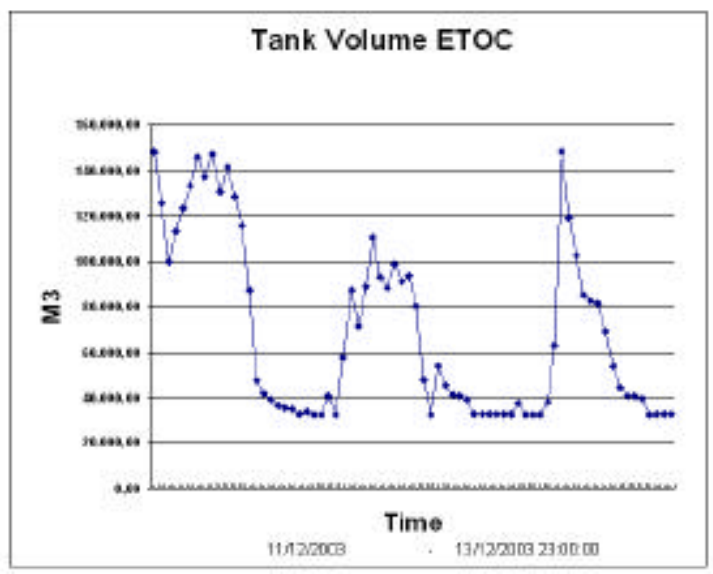

Fig. 12. Tank Volume Etoc

\section{CONCLUSIONS AND FURTHER RESEARCH}

First results of applying predictive optimal control techniques for flow management in a large water system have been presented. An important feature of this application is that it solves an optimal control problem involving open channels for water transport and pressurized water sections simultaneously, taking into account the different dynamic behaviours thereof. This is a representative example of how the proposed predictive control approach works on the complete, and much larger, model of the network. A thorough off-line testing of the application on the complete network is currently underway and the online implementation in the Santiago telemetry system is planned for 2005 .

\section{ACKNOWLEDGEMENTS}

The research project has been partly carried out by Spanish CICYT ( ref. DPI2002-03500), Research Commission of the Generalitat of Catalunya (ref.
2001SGR00236) and under a contract between Aguas Andinas and CLABSA. The contribution of the Aguas Andinas staff in supplying data and validating the experiments is gratefully acknowledged.

\section{REFERENCES}

Brdys, M. A., Ulanicki, B. (1994) Operational control of water systems: Structures, algorithms and applications Prentice Hall International, UK.

Camacho, E.F. and C. Bordons (1999). "Model Predictive Control" in Advanced Textbooks in Control and Signal Processing. Springer. London.

Cembrano, G., Quevedo, J. (1999), Optimization in Water Networks Computing and Control for the Water Industry (R. Powell, K. S. Hindi eds.) Research studies Press, UK.

Cembrano, G., Wells G., Quevedo J., Pérez R., Argelaguet R. (2000). "Optimal Control of a Water Distribution Network in a Supervisory Control System". Control Engineering Practice $\left(\mathrm{n}^{\circ} 10\right)$. Elsevier. Great Britain.

Cembrano, G., Quevedo J., Salamero, M., Puig, V., Figueras, J. and J. Martí (2004). "Optimal

Control of Urban Drainage Systems". Control Engineering Practice $\left(\mathrm{n}^{\circ} 12\right)$. Elsevier. Great Britain.

GAMS (1997) The Solver Manuals GAMS. Development Corporation. Washington DC.

Griñó R. (1991) "Neural Networks for Water Demand Time-Series Forecasting" Lecture Notes in Computer Science Vol. 540 (A. Prieto ed. ) Springer Verlag., New York-HeidelbergBerlin

Maksimivic C., Butler D., Memon A. A.. K (2003). Advances in Water Supply Management. Swets \& Zeitlinger, The Netherlands.

Meirlaen, J. (2002), "Immission based real-time control of the integrated urban wastewater system", PhD Gent University.

Price, R. K (2000). "Hydroinformatics and Urban Drainage: An Agenda for the $21^{\text {st }}$ Century" Journal of Hydroinformatics Vol.2 No.2 IWA Publishing.

Quevedo, J., Cembrano, G., Gutiérrez, L. \& Valls, A. (1988) "Time-series Modelling of Water Demand. Study on Short-term and Long-term Preditions" Computer Applications of Water Supply and Distribution (B. Coulbeck and C. H. Orr eds.), Research Studies Press, Lechworth, UK 